\title{
CORRECTION
}

\section{Correction: Is resistance training alone an antihypertensive therapy? A meta-analysis}

Odilon Abrahin (D), Renilson Moraes-Ferreira (D), Erik Artur Cortinhas-Alves (D) and João Farias Guerreiro (D)

(c) The Author(s), under exclusive licence to Springer Nature Limited 2021

Journal of Human Hypertension (2021) 35:824; https://doi.org/10.1038/s41371-021-00590-9

Correction to: Journal of Human Hypertension https://doi.org/ 10.1038/s41371-021-00582-9

The original version of this article unfortunately contained a mistake in figure 5. The correct sentence should read "Forest plot resistance training in elderly $\times$ control group for changes in diastolic blood pressure". The authors apologize for the mistake. The original article has been corrected. 